\title{
The role of $\mathrm{Li}^{+}$ions in the gas phase dehydrohalogenation and dehydration reactions of $\mathrm{i}-\mathrm{C}_{3} \mathrm{H}_{7} \mathrm{Br}$ and $\mathrm{i}-\mathrm{C}_{3} \mathrm{H}_{7} \mathrm{OH}$ molecules studied by radiofrequency-guided ion beam techniques and ab initio methods
}

E. López, J. M. Lucas, J. de Andrés, M. Albertí, J. M. Bofill, and A. Aguilar

Citation: The Journal of Chemical Physics 146, 134301 (2017); doi: 10.1063/1.4979296

View online: https://doi.org/10.1063/1.4979296

View Table of Contents: http://aip.scitation.org/toc/jcp/146/13

Published by the American Institute of Physics

\section{Articles you may be interested in}

The gas-phase structure of the asymmetric, trans-dinitrogen tetroxide $\left(\mathrm{N}_{2} \mathrm{O}_{4}\right)$, formed by dimerization of nitrogen dioxide $\left(\mathrm{NO}_{2}\right)$, from rotational spectroscopy and ab initio quantum chemistry

The Journal of Chemical Physics 146, 134305 (2017); 10.1063/1.4979182

First observation of the $3^{3} \Pi_{g}$ state of $\mathrm{C}_{2}$ : Born-Oppenheimer breakdown

The Journal of Chemical Physics 146, 134306 (2017); 10.1063/1.4979293

Multistate, multichannel coupled diabatic state representations of adiabatic states coupled by conical intersections. $\mathrm{CH}_{2} \mathrm{OH}$ photodissociation

The Journal of Chemical Physics 146, 134302 (2017); 10.1063/1.4978708

Fermi resonance in $\mathrm{CO}_{2}$ : Mode assignment and quantum nuclear effects from first principles molecular dynamics

The Journal of Chemical Physics 146, 134102 (2017); 10.1063/1.4979199

Dominant conformer of tetrahydropyran-2-methanol and its clusters in the gas phase explored by the use of VUV photoionization and vibrational spectroscopy

The Journal of Chemical Physics 146, 134303 (2017); 10.1063/1.4979298

Tunneling effects in the unimolecular decay of $\left(\mathrm{CH}_{3}\right)_{2} \mathrm{COO}$ Criegee intermediates to $\mathrm{OH}$ radical products

The Journal of Chemical Physics 146, 134307 (2017); 10.1063/1.4979297

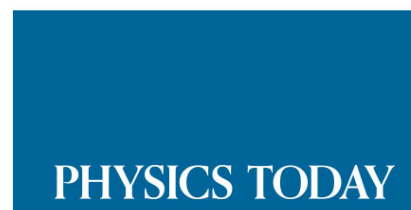

WHITEPAPERS
ADVANCED LIGHT CURE ADHESIVES

Take a closer look at what these environmentally friendly adhesive systems can do
READ NOW

PRESENTED BY

Q MASTERBOND 


\title{
The role of $\mathrm{Li}^{+}$ions in the gas phase dehydrohalogenation and dehydration reactions of $i-\mathrm{C}_{3} \mathrm{H}_{7} \mathrm{Br}$ and $i-\mathrm{C}_{3} \mathrm{H}_{7} \mathrm{OH}$ molecules studied by radiofrequency-guided ion beam techniques and $a b$ initio methods
}

\author{
E. López, ${ }^{1}$ J. M. Lucas, ${ }^{1}$ J. de Andrés, ${ }^{1}$ M. Albertí, ${ }^{1}$ J. M. Bofill, ${ }^{2}$ and A. Aguilar ${ }^{1, a)}$ \\ ${ }^{1}$ Departament de Ciència de Materials i Química Física, Institut de Química Tè̀rica i Computacional, \\ Universitat de Barcelona, Martí i Franquès, 1, 08028 Barcelona, Spain \\ ${ }^{2}$ Departament de Química Inorgànica i Química Orgànica, Institut de Química Tè̀rica i Computacional, \\ Universitat de Barcelona, Martí i Franquès, 1, 08028 Barcelona, Spain
}

(Received 10 February 2017; accepted 15 March 2017; published online 3 April 2017)

\begin{abstract}
Gas phase reactive collisions between lithium ions and $i-\mathrm{C}_{3} \mathrm{H}_{7} \mathrm{X}(\mathrm{X}=\mathrm{Br}, \mathrm{OH})$ molecules have been studied under single collision conditions in the center of mass (CM) 0.01-10.00 eV energy range using a radiofrequency-guided ion beam apparatus. Mass spectrometry analysis of the products did show the presence of $\left[\mathrm{C}_{3} \mathrm{H}_{6}-\mathrm{Li}\right]^{+},[\mathrm{HX}-\mathrm{Li}]^{+}, \mathrm{C}_{3} \mathrm{H}_{7}{ }^{+}$, and $\mathrm{C}_{2} \mathrm{H}_{3}{ }^{+}$as well as of the $\left[\mathrm{Li}-i-\mathrm{C}_{3} \mathrm{H}_{7} \mathrm{Br}\right]^{+}$ adduct while $\left[\mathrm{Li}-i-\mathrm{C}_{3} \mathrm{H}_{7} \mathrm{OH}\right]^{+}$was hardly detected. For all these reactive processes, the corresponding cross sections have been measured in absolute units as a function of the $\mathrm{CM}$ collision energy. Quantum chemistry ab initio calculations done at the second order Möller Plesset level have provided relevant information on the topology of the potential energy surfaces (PESs) where a reaction takes place allowing the characterization of the stationary points on the respective PESs along their reaction pathways. The connectivity of the different stationary points localized on the PESs was ensured by using the intrinsic reaction coordinate (IRC) method, confirming the adiabatic character of the reactions. The main topology features of the reactive PESs, in the absence of dynamical calculations, were used to interpret at the qualitative level the behavior of the experimental excitations functions, evidencing the role played by the potential energy barriers on the experimental dynamics of the reactions. Reaction rate constants at $303.2 \mathrm{~K}$ for different reactions have been calculated from measured excitation functions. Published by AIP Publishing. [http://dx.doi.org/10.1063/1.4979296]
\end{abstract}

\section{INTRODUCTION}

Ion-molecule reactions take part frequently around us in very varied and important nature stages. The interest for this type of reactions extends to various research fields of physical chemistry and chemical physics areas, such as atmospheric chemistry processes ${ }^{1,2}$ or those related to astrochemistry, ${ }^{3}$ gas-phase catalysis, plasma formation, ${ }^{4}$ and even some charge transfer processes,,, 6 and also those involved in biological systems. ${ }^{7-9}$ Among the mentioned areas, those related to our planet's atmospheric processes (and of other planets and moons within the solar system too) are particularly interesting since they provide information related to the origin of the universe and its evolution to the present day.

In order to study such ion-molecule reactions in the few $\mathrm{eV}$ collision energy range, a Radio Frequency Guided Ion Beam $(\text { RF-GIB })^{10}$ apparatus has been developed over the last 10 years in our laboratory. This has been used to research adducts' formation of alkali ions with polar ${ }^{11}$ and nonpolar molecules ${ }^{12}$ and more recently, some reactions involving halogenated organic compounds and alcohols as commented below.

\footnotetext{
a) Author to whom correspondence should be addressed. Electronic mail: a.aguilar@ub.edu
}

Dehydrohalogenation and dehydration of halogenides and alcohols induced by alkali ion collisions were observed in the late 1970s, by Wieting et al. ${ }^{13}$ and also by Allison and Ridge. ${ }^{14,15}$ They observed that ion-molecule reactivity depended mainly on the halogenide or alcohol nature and also on the particular alkali ion, lithium being the most reactive. A possible reaction mechanism was proposed. ${ }^{15}$ Using crossed beam techniques, Creasy and Farrar studied the dehydrohalogenation of some propyl chloride and propyl bromide isomers induced by collisions with low energy $\mathrm{Li}^{+}$, measuring branching ratios for different reaction channels ${ }^{16}$ at fixed collision energies, and also the similarly induced t-butanol dehydration in the gas phase. ${ }^{17}$

In our previous studies on ion-molecule dehydrohalogenation or dehydration reactions, ${ }^{18-22}$ we reported excitation functions for different reaction channels including some for previously not-described reactions. ${ }^{14-17}$ These studies were complemented by $a b$ initio calculations with which it proved possible to characterize the stationary points associated with the different reaction channels in the ground singlet state potential energy surface (PES) on which the adiabatic reactive processes took place at low collision energies. It is a well-known fact that alkali ions, on colliding with neutral molecules at low enough pressure, can form stable ion-molecule adducts, ${ }^{23}$ and in fact our experiments in 
single collision conditions clearly confirm such formation of an adduct before the system evolves to products where the alkali ion is coordinated either with the unsaturated hydrocarbon or with the removed molecule. Besides simple eliminations, on increasing collision energies our experiments detected adduct decompositions leading to a carbocation and the corresponding alkali hydroxide (in the case of ion-alcohol reactions) or halide (in ion-halogenide ones). This additional reaction channel involving the heterolytic cleavage of the original halogen atom (or the $\mathrm{OH}$ group)-carbon chemical bond has not previously described.

In this work, we study reactive processes taking place between lithium cations and the $i-\mathrm{C}_{3} \mathrm{H}_{7} \mathrm{X}(\mathrm{X}=\mathrm{Br}, \mathrm{OH})$ molecules in the $0.00-10.00 \mathrm{eV}$ collision energy range, all reactants being in their singlet electronic ground state. In the light of previous experiments, we expected to observe [ $\mathrm{Li}-i$ $\left.\mathrm{C}_{3} \mathrm{H}_{7} \mathrm{X}\right]^{+}$adduct formation at low collision energies as well as the elimination reactions leading to the products shown in reactions (1) and (2),

$$
\begin{aligned}
& \mathrm{Li}^{+}+i-\mathrm{C}_{3} \mathrm{H}_{7} \mathrm{X} \rightarrow\left[\mathrm{C}_{3} \mathrm{H}_{6}-\mathrm{Li}\right]^{+}+\mathrm{HX}, \\
& \mathrm{Li}^{+}+i-\mathrm{C}_{3} \mathrm{H}_{7} \mathrm{X} \rightarrow \mathrm{C}_{3} \mathrm{H}_{6}+[\mathrm{HX}-\mathrm{Li}]^{+},
\end{aligned}
$$

where $\mathrm{X}=\mathrm{Br}$, OH being reaction products (1) and (2), while the channel leading to $\left[\mathrm{Li}-i-\mathrm{C}_{3} \mathrm{H}_{7} \mathrm{X}\right]^{+}$formation will hereafter be referred to as (0). In the collision energy range studied, in addition to reactions (1) and (2), a decomposition can be expected to take place,

$$
\mathrm{Li}^{+}+i-\mathrm{C}_{3} \mathrm{H}_{7} \mathrm{X} \rightarrow\left[\mathrm{C}_{3} \mathrm{H}_{7}\right]^{+}+\mathrm{LiX}
$$

And, on increasing still more the energy, the $\mathrm{C}_{3} \mathrm{H}_{7}{ }^{+}$formed in (3) can be expected to further decompose,

$$
\left[\mathrm{C}_{3} \mathrm{H}_{7}\right]^{+} \rightarrow\left[\mathrm{C}_{2} \mathrm{H}_{3}\right]^{+}+\mathrm{CH}_{4},
$$

while other possible $\mathrm{C}_{3} \mathrm{H}_{7}{ }^{+}$decomposition channels have not been observed. ${ }^{24-26}$ To the best of our knowledge, neither reaction (3) nor (4) for the systems reported here has been described in the bibliography, nor were reactions (2) and (3) observed in earlier studies of the same. ${ }^{14,15}$ In this work in Section II a brief description on the experimental setup and the details of the quantum chemistry calculations are given. The experimental and computational results for the $\mathrm{Li}^{+}+i-\mathrm{C}_{3} \mathrm{H}_{7} \mathrm{Br}$ dehydrohalogenation reactions are shown in Section III, while Section IV reports on the equivalent information for the $\mathrm{Li}^{+}+i-\mathrm{C}_{3} \mathrm{H}_{7} \mathrm{OH}$ dehydration reaction. Finally, a discussion and an interpretation of the experimental results at the light of the $a b$ initio quantum chemistry calculations followed by a few conclusions are given in Sections V and VI, respectively.

\section{EXPERIMENTAL SETUP AND QUANTUM STRUCTURE CALCULATIONS}

\section{A. Brief description of the experimental setup}

The RF-GIB setup used in this work has been extensively described in the bibliography, ${ }^{10}$ so only a brief outline is given here. In the present study, a pure ${ }^{6} \mathrm{Li}^{+}\left({ }^{1} \mathrm{~S}_{0}\right)$ beam, formed by the thermionic effect by heating an aluminosilicate pellet (HeatWave Laboratories) to 1000-1200 K, is mass-selected by a quadrupole filter. Ions are collimated and focused into an octopole ion guide containing the target gas at low pressure with a thermal state distribution. The octopole field both guides and collimates the primary ion beam and focuses the ion products to the detector after their mass selection. Gaseous pure and dry $i-\mathrm{C}_{3} \mathrm{H}_{7} \mathrm{X}(\mathrm{X}=\mathrm{Br}, \mathrm{OH})$ are introduced in the octopole (the scattering reaction cell) through a conduit and flow-controlled by a fine-pitch needle valve. The entire system is under very low pressure conditions (high vacuum), the experimental background pressure being maintained in the $1 \times 10^{-6}$ to $1 \times 10^{-7} \mathrm{mbar}$ range, and the pressure in the target gas cell is low enough to ensure single collision conditions (about $1 \times 10^{-5} \mathrm{mbar}$ ). All systems and auxiliary electronic devices are PC-controlled with a software developed in our group using LabVIEW program (@ National Instruments).

In a routine experiment lithium ions collide with $i-\mathrm{C}_{3} \mathrm{H}_{7} \mathrm{X}$ molecules at a laboratory frame (LF) with the energy measured using the retarding potential analysis method ${ }^{27}$ employing the octopole guide as the retarding energy analyzer and then measuring the intensity of the primary $\left(I_{\mathrm{o}}\right)$ and product $\left(I_{\mathrm{i}}\right)$ ions. This gives a nearly Gaussian ${ }^{10,27}$ ion energy distribution with some uncertainty measured by its full width at half-maximum (FWHM). Assuming stationary target molecules, each collision energy in the LF can be associated with a single collision energy $\mathrm{E}_{0}$ in the $\mathrm{CM}$ frame, which takes into account the uncertainty of the ion beam energy distribution. Considering also the Doppler broadening on the ion beam energy distribution due to the fact that target molecules are actually not stationary, ${ }^{28-30}$ the reactive cross section at the $\mathrm{CM}$ collision energy $\mathrm{E}_{0}$ is given by

$$
\sigma_{\exp }\left(E_{0}\right)=\frac{I_{i}}{I_{0} n l}
$$

$n$ and $l$ being the target gas density in the reaction cell and its effective path length, respectively. Previous calibration experiments of the experimental setup using results described by Koizumi and Armentrout ${ }^{23}$ allows giving cross sections in absolute units with an uncertainty of $\sim 30 \%$. In the present experiments FWHM for $\mathrm{Li}^{+}$was $\sim 0.20 \mathrm{eV}$.

\section{B. Details on the quantum chemistry calculations}

A complete understanding of the experimental data requires the knowledge of the interactions between reactants that is reflected in the topography of the PES on which reactive processes take place. For the reactions studied here and taking into account the closed-shell electron configuration of $i-\mathrm{C}_{3} \mathrm{H}_{7} \mathrm{Br}, i-\mathrm{C}_{3} \mathrm{H}_{7} \mathrm{OH}$, and $\mathrm{Li}^{+}$, it can be expected that reactions (1)-(3) will proceed adiabatically on a single potential energy hypersurface. With these assumptions and for each reactive system, the potential energy profile evolution from reactants to final products on the ground singlet PESs has been characterized. The main features of the PESs along the reaction path were obtained by $a b$ initio electronic structure calculations, using a methodology which has given good results in previous works. ${ }^{22}$ It functions by locating and characterizing stationary points at the Möller Plesset (MP2) ${ }^{31-34}$ level using the 6-31G Pople basis set including polarization functions: $p$ for each hydrogen atom and $d$ for each heavy atom. Geometries and energies of the different stationary points localized 
along the reaction path were fully optimized as well as those of the reactants and products. Moreover, a complete analysis of the Hessian matrix was made to ascertain the nature of the PES' stationary points. The corresponding zero point energies (ZPEs) were also obtained using the harmonic approximation. Electronic structure calculations were done using the GAUSSIAN 2003 package, in its Gaussian 03 revision E.01 version. ${ }^{33-35}$ Dynamic correlation energies at the MP2 level have been calculated using both the full- and frozen-core approaches in order to choose the best option, fully understanding that the former does not describe accurately the complexes involving both ion- $\pi$ interactions and alkali cations, ${ }^{36}$ as in this case. Connectivity between the stationary points on the reaction PES along the reaction path was ensured by applying the intrinsic reaction coordinate (IRC) $)^{37-39}$ method.

\section{EXPERIMENTAL RESULTS AND CALCULATIONS ON THE $\mathrm{Li}^{+}+i-\mathrm{C}_{3} \mathrm{H}_{7} \mathrm{Br}$ SYSTEM}

\section{A. Experimental reactive excitation functions in $\mathrm{Li}^{+}+i-\mathrm{C}_{3} \mathrm{H}_{7} \mathrm{Br}$ collisions}

Before carrying out measurements of possible reactive cross section in collisions between $\mathrm{Li}^{+}$and $i-\mathrm{C}_{3} \mathrm{H}_{7} \mathrm{Br}$ molecules, a mass scan was performed at different collision energies in the 1-200 units of mass/charge $(\mathrm{m} / \mathrm{z})$ ratio range to characterize the different ionic products formed. Ionic products signals at $128,48,88,43$, and $27 \mathrm{~m} / \mathrm{z}$ units were found that, in the absence of any possible pollutant, can be respectively associated with the species, $\left[\mathrm{Li}-i-\mathrm{C}_{3} \mathrm{H}_{7} \mathrm{Br}\right]^{+},\left[\mathrm{Li}-\mathrm{C}_{3} \mathrm{H}_{6}\right]^{+}$, $[\mathrm{HBr}-\mathrm{Li}]^{+},\left[\mathrm{C}_{3} \mathrm{H}_{7}\right]^{+}$, and $\left[\mathrm{C}_{2} \mathrm{H}_{3}\right]^{+}$which were formed via reaction channels (0), (1), (2), (3), and (4). It is worth noting that the $\mathrm{Li}^{+}$-induced $i-\mathrm{C}_{3} \mathrm{H}_{7} \mathrm{Br}$ dehydrohalogenation was not among the reactions studied by Allison and Ridge. ${ }^{15}$ Such work was particularly relevant in chemical kinetics since, from their results, the authors do deduce an empirical description of the respective reactive potential surfaces, which helps to interpret the experimental observations.

Cross sections for the five reaction channels observed as a function of the CM energies are shown in Fig. 1. The excitation function for the adduct (0) formation is shown in Fig. 1(a). There, it can be seen that the cross section takes high values at low energies and then quickly decreases on increasing collision energy. This adduct has been characterized in a fairly wide energy range (from around 0.50 to $6.00 \mathrm{eV}$ ), while the large experimental uncertainties are precluding obtaining reliable values below $0.50 \mathrm{eV}$. The functions' shape is the one to be expected for reactions without potential energy barrier, as are many ion-molecule reactions, currently interpreted in terms of the simple Giosmousis-Stevenson-Langevin capture model (LGS)..$^{40}$

The excitation functions for dehydrohalogenation via channels (1) and (2) can be seen in Fig. 1(b). The dominant reaction is that leading to $\left[\mathrm{C}_{3} \mathrm{H}_{6}-\mathrm{Li}\right]^{+}$, with the lithium ion becoming attached to the unsaturated $\mathrm{C}_{3} \mathrm{H}_{6}$ product after inducing $\mathrm{HBr}$ elimination. When compared with channels (0) and (2), this channel shows larger cross sections than both of them, while those for $[\mathrm{HBr}-\mathrm{Li}]^{+}$formation via channel (2) are higher than values measured for the reactants adduct cross section. The shape of the excitation function for
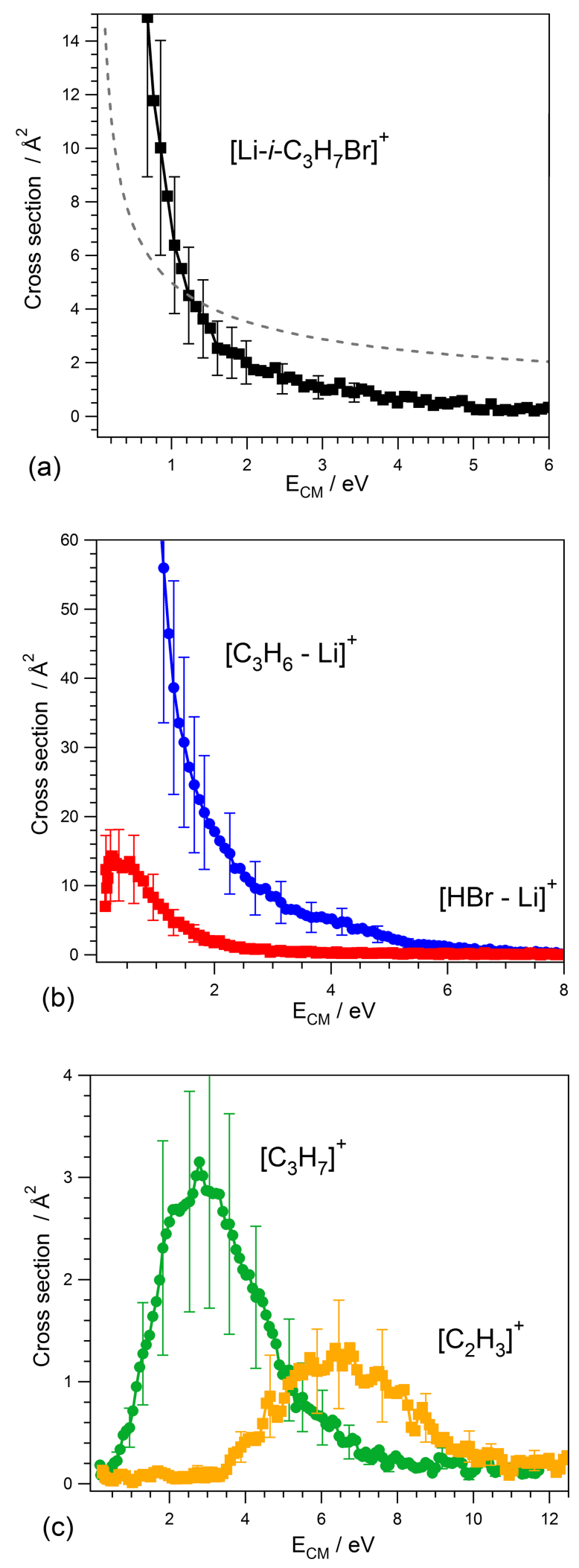

FIG. 1. Reactive cross section versus $\mathrm{CM}$ collision energy in the $\mathrm{Li}^{+}$ $+i-\mathrm{C}_{3} \mathrm{H}_{7} \mathrm{Br}$ system for (a) $\left[\mathrm{Li}-i-\mathrm{C}_{3} \mathrm{H}_{7} \mathrm{Br}\right]^{+}$adduct formation. Dashed line shows the cross section energy dependence according to the LSG model; (b) (solid blue circle) reaction (1) and (solid red square) reaction (2); (c) (solid green circle) reaction (3) and (solid yellow square) reaction (4).

$[\mathrm{HBr}-\mathrm{Li}]^{+}$formation shows a very small energy threshold, pointing out that the reaction can proceed at very low energies and that, if there is an energy requirement for this channel, it 
TABLE I. Calculated reaction energies $\left(\Delta_{\mathrm{r}} E\right)$ and enthalpies $\left(\Delta_{\mathrm{r}} H^{\mathrm{o}}\right)$ at $0 \mathrm{~K}$ for the three reactions in $\mathrm{Li}^{+}+i-\mathrm{C}_{3} \mathrm{H}_{7} \mathrm{Br}$ collisions (see text), all energies being given in $\mathrm{eV}$.

\begin{tabular}{lccc}
\hline \hline & Reaction (1) & Reaction (2) & Reaction (3) \\
\hline$\Delta_{\mathrm{r}} E$ & 0.116 & 0.294 & 0.825 \\
$\Delta_{\mathrm{r}} H^{\mathrm{o}}$ & -0.091 & 0.090 & 0.685 \\
\hline \hline
\end{tabular}

is very close to $0 \mathrm{eV}$, although experimental uncertainty at low energies precludes giving this value with enough confidence. The function for channel (2) shows a flat maximum located around at $0.30-0.40 \mathrm{eV}$, with a cross section value of 14.0 $\AA^{2}$, later decreasing when the collision energy increases and becoming nearly zero at about $3.0 \mathrm{eV}$.

In Fig. 1(c) is reported the cross section energy dependence for reaction (3), the dissociative process in $\mathrm{Li}^{+}+i$ $\mathrm{C}_{3} \mathrm{H}_{7} \mathrm{Br}$ collision leading to $\mathrm{C}_{3} \mathrm{H}_{7}{ }^{+}$. The functions' shape clearly shows an experimental energy threshold around $0.5 \mathrm{eV}$, and it displays also a clear maximum at around $3.0 \mathrm{eV}$ with a cross section value of about $3.0 \AA^{2}$ followed by a smooth decrease at higher energies. In the same figure is also plotted the excitation function for $\mathrm{C}_{2} \mathrm{H}_{3}{ }^{+}$formation by $\mathrm{C}_{3} \mathrm{H}_{7}{ }^{+}$fragmentation via reaction (4), which presents an energy threshold of around $3.5 \mathrm{eV}$, reaches a maximum at about $6.5 \mathrm{eV}$, and then decreases regularly at higher energies. This means that channel (4) has a much higher energy requirement than (2) and (3) and that, considering its unimolecular character, it can happen only when the internal energy of the $\mathrm{C}_{3} \mathrm{H}_{7}{ }^{+}$produced in reaction (3) is large enough to lead to its fragmentation..$^{25,41}$

\section{B. Quantum chemistry characterization of the stationary points along the reaction pathway on the ground PES for the $\left[\mathrm{Li}-i-\mathrm{C}_{3} \mathrm{H}_{7} \mathrm{Br}\right]^{+}$ reactive system}

It is well known that numerical results in quantum chemistry calculations for the energetics of chemical reactions are sensitive to the basis set and level of theory used. Moreover, there is no experimental information on the formation enthalpies for ion-molecule products in reactions (1) and (2). With this in mind and in order to obtain consistent calculated reaction enthalpy values for the reactions studied here, some
TABLE II. Energies $(\triangle E)$, zero point energies $(Z P E)$, and enthalpies at $0 \mathrm{~K}$ $\left(\Delta H^{\circ}\right)$ referred to reactants (see text) for minima $(\mathrm{M})$ and transition states (TS) located on the ground singlet PES of the $\left[\mathrm{Li}-i-\mathrm{C}_{3} \mathrm{H}_{7} \mathrm{Br}\right]^{+}$reactive system. All energies are given in $\mathrm{eV}$.

\begin{tabular}{lrcccc}
\hline \hline & M1 & TS1 & M2 & TS2 & M3 \\
\hline$\Delta E$ & -1.464 & -0.322 & -0.350 & -0.223 & -0.853 \\
$\Delta Z P E$ & 0.024 & -0.135 & -0.141 & -0.172 & -0.160 \\
$\Delta H^{\mathrm{o}}$ & -1.440 & -0.457 & -0.491 & -0.395 & -1.013 \\
\hline \hline
\end{tabular}

calculation tests using different basis sets among the best of those employed for these systems $(6-31 \mathrm{G}(\mathrm{d}, \mathrm{p})$ and $6-311 \mathrm{G}$ also including diffuse functions) have been done at different levels of theory (MP2 including full electron correlation and frozen core approximations) as well as at the density functional theory (DFT) ${ }^{42,43}$ level using the B3LYP functional. ${ }^{44}$ Some of these set-methodology combinations gave a similar behavior or tendencies, while others were disappointing. From a detailed analysis of the different calculations, the calculated reaction enthalpies at $0 \mathrm{~K}$ and reaction energies were obtained using the 6-31G(d,p) basis set and the frozen-core approximation at the MP2 level and are given in Table I.

To help with the interpretation of experimental results and using the selected basis set and level of theory, ab initio calculations were started to localize and fully characterize possible stationary points along the reaction path from reactants to products assuming that the reaction evolves adiabatically on the ground singlet PES. In Table II energies of the different minima (M1, M2, M3) and transition states (TS1, TS2) located along the reaction path are given, while Figure 2 shows a schematic representation of the electronic energy including the zero point one ( $\Delta H^{\circ}$ referred to reactants) for the full evolution profile from asymptotic $\mathrm{Li}^{+}+i-\mathrm{C}_{3} \mathrm{H}_{7} \mathrm{Br}$ reactants to the different reaction products.

The connectivity between stationary points has been ensured by means of the IRC procedure. In Fig. 2 it can be seen clearly that reaction pathways for reactions (1) and (2) share the same evolution sequence of minima and transition states from TS1 till M3. From M3, the associated collision complex has the possibility to dissociate, either leading to reaction (1) products or, alternatively, to those for reaction

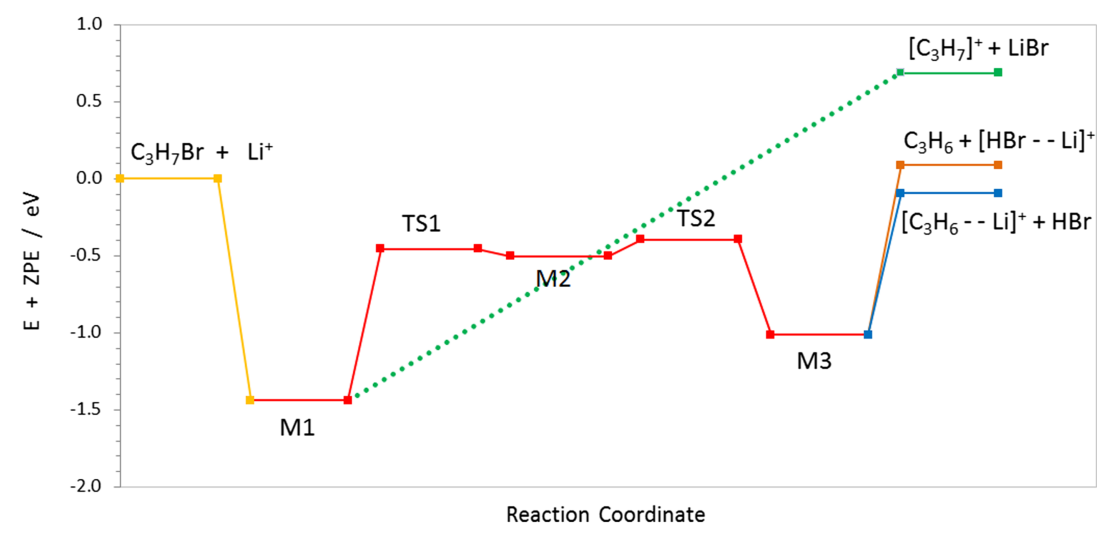

FIG. 2. Potential energy profile including ZPEs referred to reactants showing the different minima (M) and transition states (TS) along the reaction pathway on the ground singlet state PES of the $\mathrm{Li}^{+}+i-\mathrm{C}_{3} \mathrm{H}_{7} \mathrm{Br}$ reaction (see text). Continuous yellow line describes the asymptotic reactants region while blue and orange lines describe asymptotic reactions channels (1) and (2), respectively. Continuous red line shows the connectivity among M and TS on the PES' strong chemical interaction region. Dotted green line shows the pathway for $\left[\mathrm{Li}-i-\mathrm{C}_{3} \mathrm{H}_{7} \mathrm{Br}\right]^{+}(\mathrm{M} 1)$ decomposition reaction (3). 
(2). Moreover, as it is clearly shown in Fig. 2, from M1 the reactant ion-molecule adduct can evolve adiabatically on the same ground singlet PES to reaction products (3), the decomposition reaction pathway of the M1 adduct, without any additional potential energy barrier.

\section{Quantum chemistry structures of the relevant stationary points along the reaction pathway on the ground PES of the $\left(\mathrm{Li}-i-\mathrm{C}_{3} \mathrm{H}_{7} \mathrm{Br}\right)^{+}$system}

Optimized equilibrium geometries for products resulting from reactions (1)-(3) together with $i-\mathrm{C}_{3} \mathrm{H}_{7} \mathrm{Br}$ molecule, all of them optimized and characterized at the MP2 level with Hessian matrix analysis, are shown in Fig. 3(a). Chemical structures associated with stationary points (minima or transition states) localized along the reaction pathway and optimized in the same way are given in Fig. 3(b).

Following the reactants to products pathway shown in Fig. 2, the first stationary point is M1 whose structure (see Fig. 3(b)) is associated with the $\left[\mathrm{Li}-i-\mathrm{C}_{3} \mathrm{H}_{7} \mathrm{Br}\right]^{+}$adduct, with $\mathrm{Li}^{+}$being directly coordinated with $\mathrm{Br}$ at a distance of $2.417 \AA$. In this structure the reagent's electron density is modified, the corresponding new charge distribution having been calculated using the Atomic Polar Tensor (APT) method. ${ }^{45,46}$ The main charge modifications occur on lithium, bromine, and central carbon atom (hereafter $\mathrm{C}_{\text {central }}$ ). Lithium initial positive charge is reduced to 0.879; the negative one on $\mathrm{Br}$ increases from -0.309 to -0.468 and the positive one of 0.396 on the central carbon atom becomes 0.611 . As the $\mathrm{Li}-\mathrm{Br}$ negative net charge increases, the $\mathrm{Br}-\mathrm{C}_{\text {central }}$ bond weakens (lengthening to $0.072 \AA$ ), and this will ease $\mathrm{HBr}$ elimination in successive reaction steps. The detailed analysis of the valence molecular orbitals of the $\left[\mathrm{Li}-i-\mathrm{C}_{3} \mathrm{H}_{7} \mathrm{Br}\right]^{+}$structure shows a negligible participation of the lithium's atomic orbital, clearly showing that the ion-molecule interaction is essentially non-covalent in nature, as was also observed in previous studies on similar systems. $^{11,19}$

The study of the reaction pathway leading from M1 to (1) and (2) products requires an exhaustive and wide characterization of the interaction energies which in the first step localizes a first order saddle point $(0.457 \mathrm{eV}$ below reactants' energy) associated with the transition state TS1. This has a single Hessian matrix negative eigenvalue with a $245.24 i \mathrm{~cm}^{-1}$ imaginary frequency. In detail, this path shows that, as the initial $\mathrm{Br}-\mathrm{C}_{\text {central }}$ distance in $\mathrm{M} 1$ increases going to TS1, the $\mathrm{CH}_{3}$ group rotates and one hydrogen atom approaches the $\mathrm{Br}$ one (up to $2.395 \AA$ ) as shown in Fig. 3(b), also lengthening the $\mathrm{Br}-\mathrm{C}_{\text {central }}$ distance from 2.051 to $3.244 \AA$. From the same figure, it can be appreciated that, on moving from M1 to $\mathrm{TS} 1$, the $\mathrm{Li}-\mathrm{Br}$ and $\mathrm{C}_{\text {central }}-\mathrm{CH}_{3}$ distances decrease to 0.134 and $0.110 \AA$, respectively. Localized charges on $\mathrm{C}_{\text {central }}$ and $\mathrm{Li}$ atoms remain almost unchanged while the electron density on the $\mathrm{Br}$ atom grows substantially, its negative charge increasing from -0.468 to -0.852 . This leads to an increase in the electropositive character of all hydrogen atoms, particularly for the one interacting with the $\mathrm{Br}$, which changes from 0.026 to 0.255 .

From the TS1 structure and following the IRC path in the sense of the negative imaginary frequency, the supermolecule reaches a shallow minimum M2 having an energy close to that
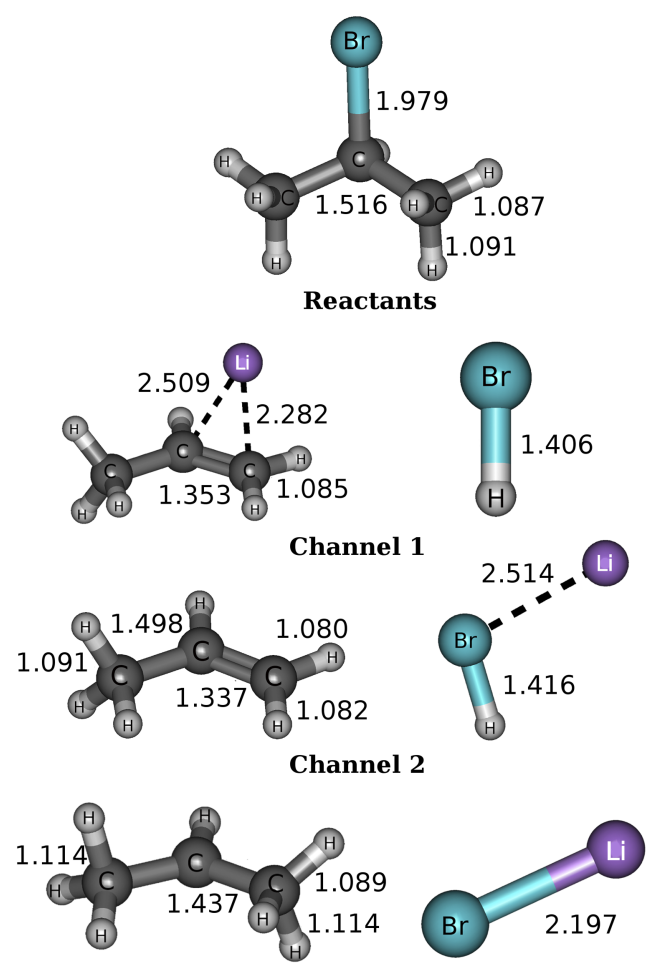

(a)

Channel 3
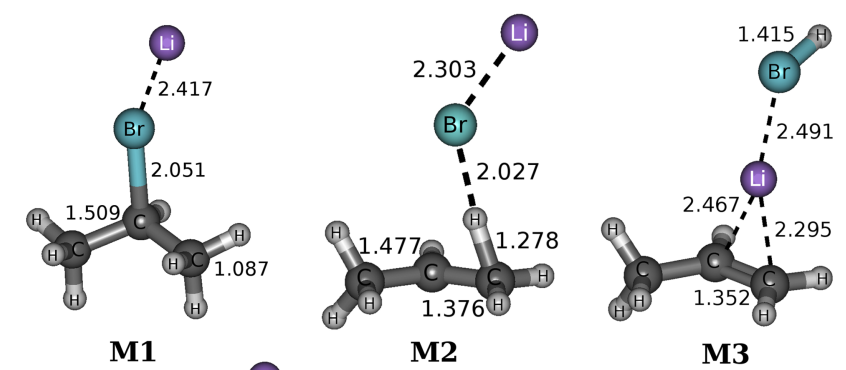

(b)
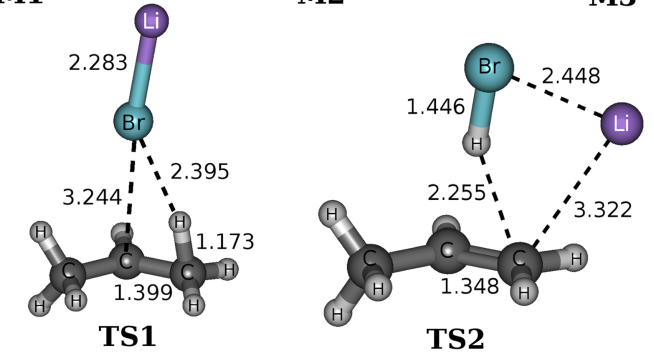

FIG. 3. (a) Equilibrium geometries of reactants and products for the three possible reactions in the $\mathrm{Li}^{+}+i-\mathrm{C}_{3} \mathrm{H}_{7} \mathrm{Br}$ system. (b) Equilibrium geometries for the different stationary points localized along the IRC reaction pathway on the PES. For simplicity only the most relevant interatomic distances (in $\AA$ ) are shown.

of TS1 (see Table II) and $0.491 \mathrm{eV}$ below reactants. Its structure is shown in Fig. 3(b), where it can be seen that in this intermediate the $\mathrm{C}_{\text {central }}-\mathrm{C}_{\text {terminal }}$ distance differs only $0.062 \AA$ from that in the isolated product molecule (Fig. 3(a)). Also, the active $\mathrm{H}$ atom approaches the $\mathrm{Br}$ one with an interatomic distance of $2.027 \AA$, still somewhat far from that calculated for the isolated molecule (1.406 $\AA$ ), and with lithium interacting with $\mathrm{Br}$ at $2.303 \AA$. In this M2 intermediate, the active hydrogen increases its net positive charge from 0.255 (in TS1) to 0.542 , while that of bromine is slightly increased to -0.883 ; the remaining hydrogen atoms have a near-zero positive charge 
and that for the terminal carbon atom of the $\mathrm{C}=\mathrm{C}$ bond is -0.286 . From M2, the reactive system evolves along the reaction path until it reaches the top of a relatively low potential energy barrier $(0.096 \mathrm{eV}$ above M2) characterized as a first order saddle point with a $104.93 i \mathrm{~cm}^{-1}$ imaginary frequency associated with the TS2 transition state whose optimized structure is shown in Fig. 3(b). In this transition state, $\mathrm{Li}^{+}$gets nearer to the $\mathrm{C}_{\text {terminal }}$ on the $\mathrm{C}=\mathrm{C}$ bond, which has the highest electron density point of the $\mathrm{C}_{3} \mathrm{H}_{6}$ fragment. In this structure, the $\mathrm{H}-\mathrm{Br}$ distance differs only in $0.040 \AA$ from the equilibrium one in the isolated molecule. In the TS2 structure shown in Fig. 3(b), it can be seen that the distances of both hydrogen and lithium centers to the carbon centers in the $\mathrm{C}=\mathrm{C}$ bond are relatively large $(>2.00 \AA)$, with the $\mathrm{H}-\mathrm{Br}-\mathrm{Li}$ centers and the $\mathrm{C}=\mathrm{C}$ carbon centers being almost located in the same plane which is practically perpendicular to the $\mathrm{C}_{3} \mathrm{H}_{6}$ fragment one. By going on from TS2 along its imaginary frequency, another M3 minimum is reached, whose structure is shown in Fig. 3(b) at $1.013 \mathrm{eV}$ below reactants. The M3 intermediate displays a structure in which the $\mathrm{Li}^{+}$is coordinated with the $\mathrm{HBr}$ molecule through interaction with the bromide atom and to the $\mathrm{C}_{3} \mathrm{H}_{6}$ molecule by the $\mathrm{C}=\mathrm{C}$ double bond, these being located in opposite sides. The APT atomic net charges on lithium, terminal carbon in the $\mathrm{C}=\mathrm{C}$ bond, and bromine centers are $0.742,-0.195$, and -0.105 , respectively, values that qualitatively justify the coordination structure in M3. As was the case for M1, valence molecular orbitals of M3 do not show significant participation of the lithium atomic orbitals, interactions being essentially non-covalent in nature. Moreover, bond distances of the $\mathrm{HBr}$ and $\mathrm{C}_{3} \mathrm{H}_{6}$ fragments in $\mathrm{M} 3$ are also very close to those calculated for separated molecules. From the M3 structure, reaction products (1) and (2) can be easily produced by a simple lengthening of the $\mathrm{Li}-\mathrm{Br}$ or $\mathrm{Li}-\mathrm{C}_{3} \mathrm{H}_{6}$ distances, respectively, as can be inferred from the $\mathrm{M} 3$ structure in Figure 3(b).

\section{EXPERIMENTAL RESULTS AND CALCULATIONS ON THE $\mathrm{Li}^{+}+i-\mathrm{C}_{3} \mathrm{H}_{7} \mathrm{OH}$ SYSTEM}

\section{A. Experimental reactive excitation function in $\mathrm{Li}^{+}+i-\mathrm{C}_{3} \mathrm{H}_{7} \mathrm{OH}$ collisions}

As in the previously presented dehydrohalogenation reactions, a mass scan in the range of 1-200 $(\mathrm{m} / \mathrm{z})$ units was done and signals obtained at 67, 49, 25, and 43 units were associated with $\left[\mathrm{Li}-i-\mathrm{C}_{3} \mathrm{H}_{7} \mathrm{OH}\right]^{+},\left[\mathrm{Li}-\mathrm{C}_{3} \mathrm{H}_{6}\right]^{+},\left[\mathrm{H}_{2} \mathrm{O}-\mathrm{Li}\right]^{+}$, and $\mathrm{C}_{3} \mathrm{H}_{7}{ }^{+}$, respectively, corresponding to the reactant ionmolecule adduct $(0)$ and to the products in reactions (1)(3). Reactive cross sections for dehydration reactions (1) and (2) as a function of the CM collision energy are shown in Fig. 4(a), while those for reaction (3) and its subsequent decomposition, reaction (4), are given in Fig. 4(b). While the ion-molecule adduct $(\mathrm{m} / \mathrm{z}=67$ units) was detected in the mass scan, the large uncertainties found when measuring the corresponding intensities precluded obtaining its excitation function.

In Fig. 4(a), it can be appreciated that the excitation function shows high cross section absolute values, and that the energy dependence seems to reveal the presence of an energy threshold in the order of a few tenths of $\mathrm{eV}$, but unfortunately
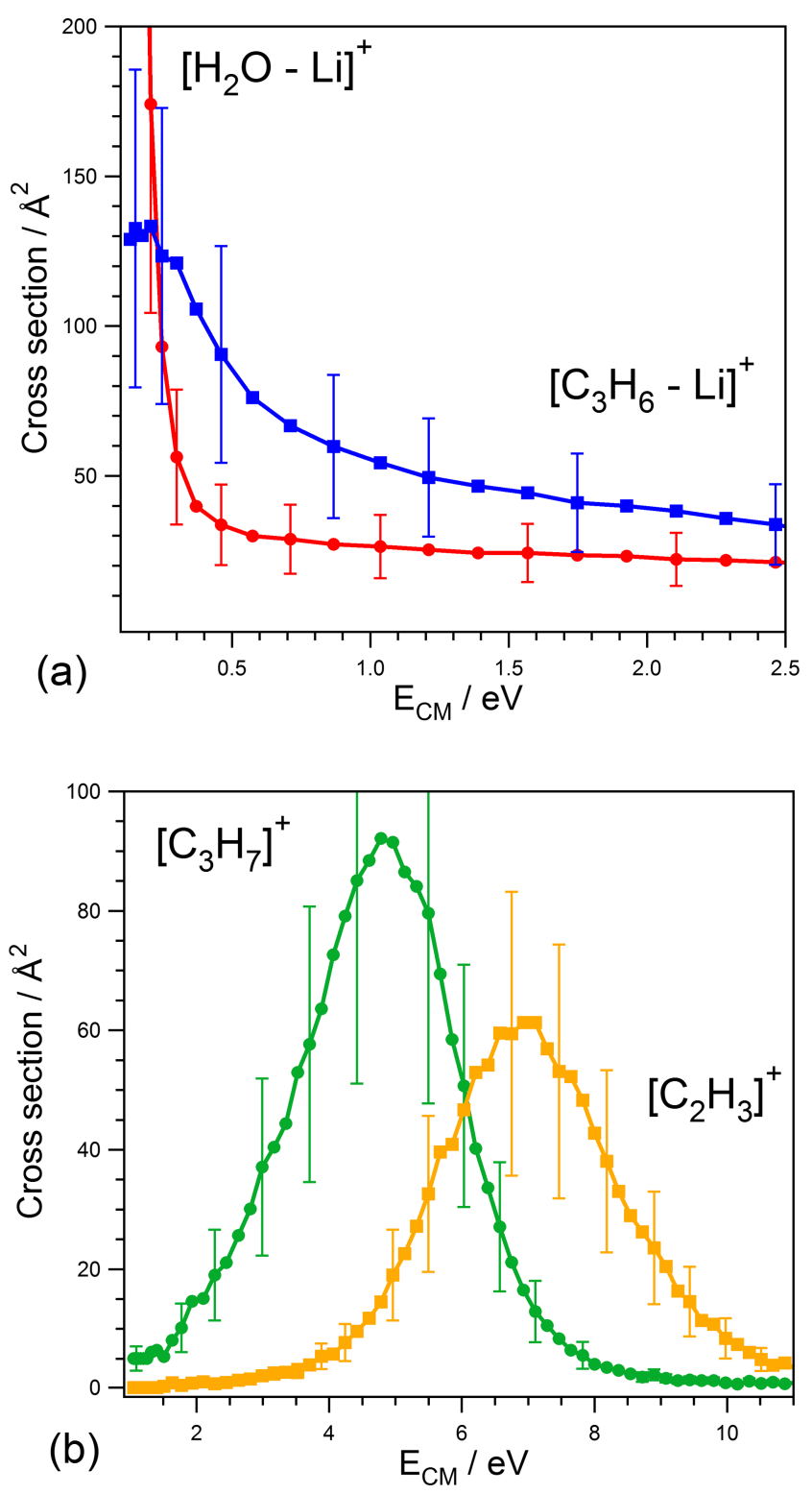

FIG. 4. Reactive cross section versus CM collision energy for the $\mathrm{Li}^{+}$ $+i-\mathrm{C}_{3} \mathrm{H}_{7} \mathrm{OH}$ system for (a) reaction channels (1) (solid blue square) and (2) (solid red circle); (b) reaction channel (3) (solid green circle) and of the $\mathrm{C}_{3} \mathrm{H}_{7}{ }^{+}$decomposition (4) (solid yellow square) (see text).

the high signal-to-noise ratio added to the FWHM uncertainty precludes its estimation with enough confidence. On the contrary, the excitation function for reaction (2) leading to $\left[\mathrm{H}_{2} \mathrm{O}-\mathrm{Li}\right]^{+}$does not show the presence of an energy threshold. In Fig. 4(b) the excitation function for the $\left[\mathrm{Li}-i-\mathrm{C}_{3} \mathrm{H}_{7} \mathrm{OH}\right]^{+}$ adiabatic decomposition shows an energy dependence of the kind expected on reactions with an energy requirement, with an experimental threshold energy of around $1.80 \mathrm{eV}$. The cross sections for reaction (1) increase with the collision energy up to a maximum value of about $90 \AA^{2}$ at around $4.80 \mathrm{eV}$, and then they decrease until disappearing at higher energies. In the same figure the excitation function for the decomposition reaction (4) shows a similar behavior with a threshold energy that can be roughly estimated as $3.0 \mathrm{eV}$ and a maximum of $65 \AA^{2}$ at $7.0 \mathrm{eV}$, and then they decrease and disappear at about $11 \mathrm{eV}$. As in the case of the $\mathrm{Li}^{+}+i-\mathrm{C}_{3} \mathrm{H}_{7} \mathrm{Br}$ system, $\mathrm{C}_{3} \mathrm{H}_{7}{ }^{+}$decomposition takes place only when the collision 
TABLE III. Calculated reaction energies $\left(\Delta_{\mathrm{r}} E\right)$ and enthalpies $\left(\Delta_{\mathrm{r}} H^{\mathrm{o}}\right)$ at $0 \mathrm{~K}$ for the three reactions in $\mathrm{Li}^{+}+i-\mathrm{C}_{3} \mathrm{H}_{7} \mathrm{OH}$ collisions (see text), all energies being given in $\mathrm{eV}$.

\begin{tabular}{lccc}
\hline \hline & Reaction (1) & Reaction (2) & Reaction (3) \\
\hline$\Delta_{\mathrm{r} E}$ & -0.211 & -0.837 & 2.101 \\
$\Delta_{\mathrm{r}} H^{\mathrm{o}}$ & -0.381 & -0.962 & 1.892 \\
\hline \hline
\end{tabular}

energy is large enough to form this ion in an internally excited form. ${ }^{25,41}$

\section{B. Quantum chemistry characterization of the stationary points along the reaction pathway on the ground PES for the $\left[\mathrm{Li}-i-\mathrm{C}_{3} \mathrm{H}_{7} \mathrm{OH}\right]^{+}$ reactive system}

For its ground singlet PES, the most relevant stationary points along the $\mathrm{Li}^{+}+i-\mathrm{C}_{3} \mathrm{H}_{7} \mathrm{OH}$ reaction pathway as well as the energetics of the different reactions have been characterized in the same way as that for the dehydrohalogenation presented in Section III, using also different basis sets and levels of theory. Table III gives calculated reaction energies $\left(\Delta_{\mathrm{r}} E\right)$ and enthalpies $\left(\Delta_{\mathrm{r}} H^{\mathrm{o}}\right)$ at $0 \mathrm{~K}$ for reactions (1)-(3) at the MP2 level in the frozen-core approximation and using the 6-31G(d,p) basis set.

It can be seen that reactions (1) and (2) are both exoergic and exothermic, while (3) is endoergic and endothermic, the inclusion of the ZPE leading to a reduced energy content of the final reaction products. Ab initio calculations were also performed to localize and fully characterize all the possible stationary points along the reaction path from reactants to products. Energies for the different minima (M1, M2, M3) and transition states (TS1, TS2) located along the reaction path on the same PES are given in Table IV while Fig. 5 shows a schematic energy profile evolution of the reaction system from reactants to products where energies include the ZPE $\left(\Delta_{\mathrm{r}} H^{\mathrm{o}}\right)$ with all values referred to reactants. As can be seen when comparing data reported in Tables II and IV and Figures 2 and 5, $i-\mathrm{C}_{3} \mathrm{H}_{7} \mathrm{Br}$ dehydrohalogenation and $i$ - $\mathrm{C}_{3} \mathrm{H}_{7} \mathrm{OH}$ dehydration reactions show a completely similar sequence of minima and saddle points (M1 $\rightarrow$ TS1 $\rightarrow$ M2 $\rightarrow \mathrm{TS} 2 \rightarrow \mathrm{M} 3$ ) along the reaction pathway in the different reaction channels, the connectivity between stationary points for the latter being also proved using the IRC method. As shown in Fig. 5 the M1 ion-molecule adduct can evolve adiabatically on
TABLE IV. Energies $(\triangle E)$, zero point energies $(Z P E)$, and enthalpies at $0 \mathrm{~K}$ $\left(\triangle H^{\circ}\right)$ referred to reactants (see text) for minima $(\mathrm{M})$ and transition states (TS) located on the ground singlet PES of the $\left[\mathrm{Li}-i-\mathrm{C}_{3} \mathrm{H}_{7} \mathrm{OH}\right]^{+}$reactive system. All energies are given in $\mathrm{eV}$.

\begin{tabular}{lrrrrr}
\hline \hline & \multicolumn{1}{c}{ M1 } & TS1 & M2 & TS2 & M3 \\
\hline$\Delta E$ & -2.004 & 0.434 & -1.332 & -1.287 & -1.871 \\
$\Delta Z P E$ & 0.049 & -0.155 & -0.073 & -0.078 & -0.078 \\
$\Delta H^{\mathrm{o}}$ & -1.955 & 0.279 & -1.405 & -1.375 & -1.949 \\
\hline \hline
\end{tabular}

the ground singlet PES to final products according with reaction channels (1) or (2) or, alternatively, decompose to reaction products (3) simply overcoming the reaction enthalpy of the process, the $\mathrm{C}_{3} \mathrm{H}_{7}{ }^{+}$product being able to further decompose at higher collision energies.

\section{Quantum chemistry structures of the relevant stationary points along the reaction pathway on the ground PES of the $\left[\mathrm{Li}-\mathrm{i}-\mathrm{C}_{3} \mathrm{H}_{7} \mathrm{OH}\right]^{+}$ reactive system}

Optimized geometries for the reactant molecules and for all products not produced also in the $\mathrm{Li}^{+}+i-\mathrm{C}_{3} \mathrm{H}_{7} \mathrm{OH}$ reaction, characterized at the MP2 level and a Hessian matrix analysis, are shown in Fig. 6(a) while those associated with the different stationary points localized along the reaction pathway are plotted in Fig. 6(b). In Fig. 5 it can be seen how the system evolves into $\left[\mathrm{Li}-i-\mathrm{C}_{3} \mathrm{H}_{7} \mathrm{OH}\right]^{+}$(associated with the stationary point $\mathrm{M} 1$ and located $1.955 \mathrm{eV}$ below reactants). This adducts' geometry is shown in Fig. 6(b), where it can be seen that $\mathrm{Li}^{+}$ is coordinated with $\mathrm{O}$ at a distance of $1.841 \AA$, causing the $\mathrm{O}-\mathrm{C}_{\text {central }}$ distance to increase from $1.431 \AA$ to $1.474 \AA$, the $\mathrm{C}-\mathrm{O}-\mathrm{Li}$ angle being $118.36^{\circ}$. As was to be expected, the ion-molecule interaction modifies the electron density distribution of the neutral molecule, changing the localized charge of the oxygen atom from -0.609 to -0.776 while, the lithium one decreases to 0.845 . At the same time, the $\mathrm{C}_{\text {central }}$ net charge remains almost unchanged (from 0.537 without interaction to 0.543 in the adduct) and the terminal carbon atoms increase slightly their very small net negative charge as do the $\mathrm{H}$ atoms their positive one (by around 0.03). Also, the hydroxyl hydrogen net change is about 0.076 larger than that of the other ones. There is then a slight increase in the acidic character of all hydrogen atoms.

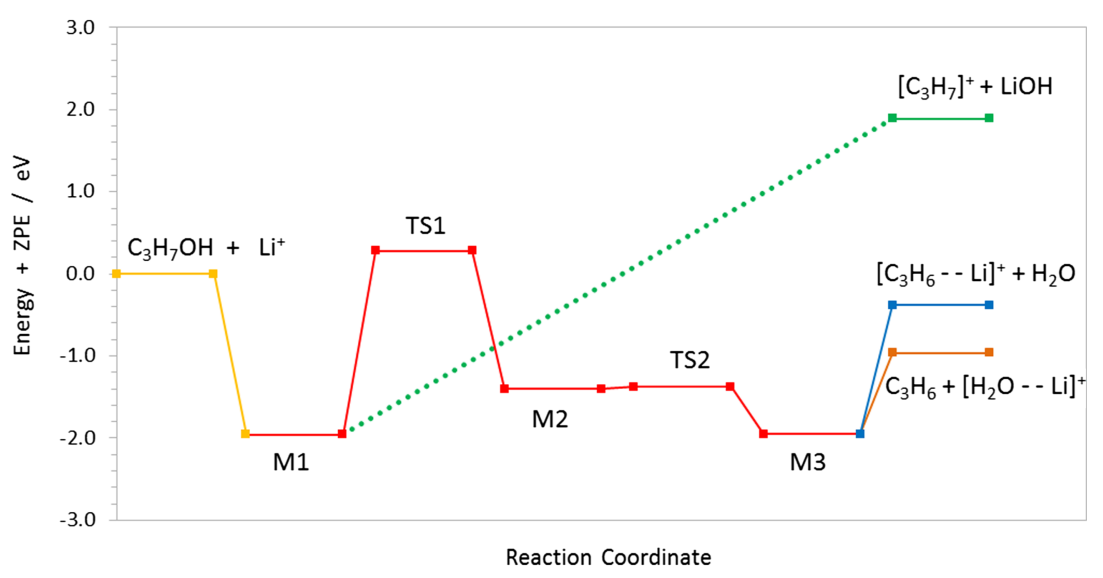

FIG. 5. Potential energy profile including ZPEs referred to reactants showing the different minima $(\mathrm{M})$ and transition states (TS) along the reaction pathway on the ground singlet states PES of the $\mathrm{Li}^{+}+i-\mathrm{C}_{3} \mathrm{H}_{7} \mathrm{OH}$ reaction (see text). Continuous yellow line describes the asymptotic reactants region, while blue and orange lines describe asymptotic reactions channels (1) and (2), respectively. Continuous red line shows the connectivity among $\mathrm{M}$ and TS on the PES' strong chemical interaction region. Dotted green line shows the pathway for $\left[\mathrm{Li}-i-\mathrm{C}_{3} \mathrm{H}_{7} \mathrm{OH}\right]^{+}$(M1) decomposition reaction (3). 


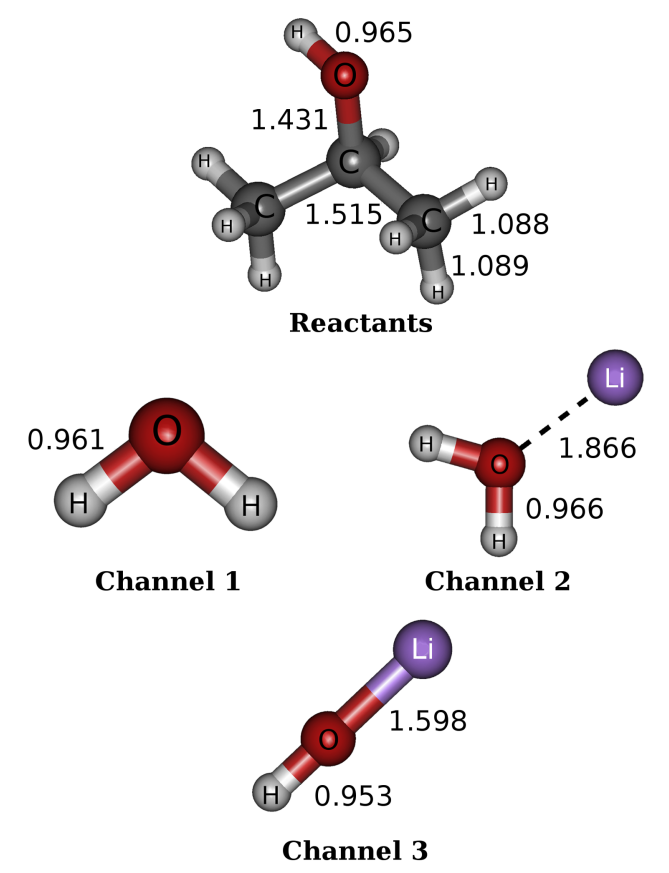

(a)

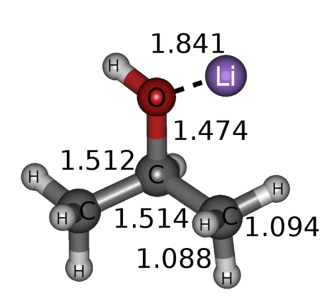

M1

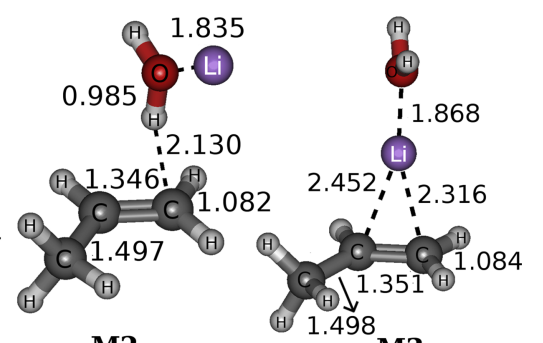

M2

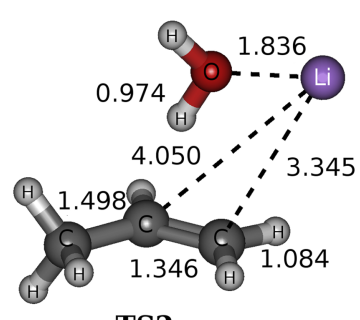

(b)

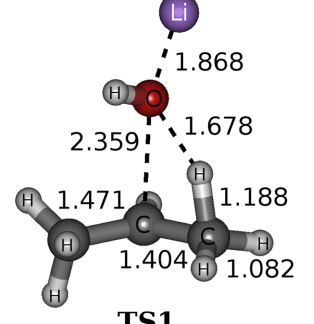

TS1

FIG. 6. (a) Equilibrium geometries of reactants and products for the three possible reactions in the $\mathrm{Li}^{+}+i-\mathrm{C}_{3} \mathrm{H}_{7} \mathrm{OH}$ system. (b) Equilibrium geometries for the different stationary points localized along the IRC reaction pathway on the PES. For simplicity only the most relevant interatomic distances (in $\AA$ ) are shown.

Following the reaction pathway, the M1 structure, after being properly distorted, reaches the top of a potential energy barrier (at $0.279 \mathrm{eV}$ above reactants' energy) associated with the transition state TS1 with a $917.90 i \mathrm{~cm}^{-1}$ imaginary frequency which is represented in Fig. 6(b). The evolution from M1 to TS1 along the IRC coordinate leads the $\mathrm{O}-\mathrm{C}_{\text {central }}$ bond distance to increase from $1.474 \AA$ to $2.359 \AA$ while the $\mathrm{CH}_{3}$ rotates until one hydrogen atom faces the oxygen atom at $1.678 \AA$, its bond to the $\mathrm{C}$ lengthening to $1.188 \AA$ in TS1. In this structure, the charges localized on $\mathrm{O}$ and on $\mathrm{C}_{\text {terminal }}$ atoms increase up to -1.081 and -0.349 , respectively, the net charge on the hydrogen in the $\mathrm{OH}$ group decreases to 0.321 while net charge on the hydrogen of methyl interacting significantly increases (up to 0.306), the localized net charge on lithium

(0.864) remaining practically unchanged. From TS1, the IRC evolution along the imaginary frequency leads to a very minimum M2 (at $1.405 \mathrm{eV}$ below the energy of reactants), its structure being given in Fig. 6(b). The M2 structure clearly shows that the dehydration is essentially achieved in this step, with the $\mathrm{C}_{3} \mathrm{H}_{6}$ and $\mathrm{H}_{2} \mathrm{O}$ products already formed but with both molecules interacting simultaneously with $\mathrm{Li}^{+}$. In $\mathrm{M} 2$, the distances $\mathrm{O}-\mathrm{H}(0.985 \AA)$ and $\mathrm{C}_{\text {central }}-\mathrm{C}_{\text {terminal }}(1.346 \AA)$ are very close to the equilibrium ones in the isolated molecules (0.961 $\AA$ and $1.337 \AA$, respectively). Moreover, the long distance ( $2.130 \AA$ ) between the transferred $\mathrm{H}$ atom to oxygen and the $\mathrm{C}_{\text {central }}$ makes evident that the hydrogen transfer has been completed. In the M2 structure, the electron density is highest in the $\mathrm{O}$ atom and the double bond $\mathrm{C}_{\text {terminal }}$, while the positive charge is essentially located on the lithium center having an APT charge of 0.914.

At this step in the evolution along the energy profile shown in Fig. 5, the reactive supermolecule easily overcomes a small potential energy barrier (only $0.030 \mathrm{eV}$ above the energy of the M2 minimum) and reaches a new transition state TS2 with a $115.64 i \mathrm{~cm}^{-1}$ imaginary frequency. The $\mathrm{M} 2$ structure is shown in Fig. 6(b), where it can be clearly seen that the $\mathrm{H}_{2} \mathrm{O}$ molecule, the lithium center, and the $\mathrm{C}=\mathrm{C}$ double bond all lie essentially in a plane practically perpendicular to the $\mathrm{C}_{3} \mathrm{H}_{6}$ skeleton with $\mathrm{H}$ transferred to the water pointing to the $\mathrm{C}_{\text {central }}$ and the lithium center far (3.345 $\AA$ ) from the $\mathrm{C}_{\text {terminal. }}$. The TS2 electron density distribution is quite similar to the M2 one, with the oxygen atom showing the most significant change in its localized charge from -0.827 to -0.748 . Going onwards from TS2, the system evolves into a new potential energy minimum (M3) at $-1.949 \mathrm{eV}$ with respect to the reagents' energy and almost as stable as the M1 adduct. The M3 structure is given in Figure 6(b). This structure clearly shows the lithium center as being coordinated with both $\mathrm{C}_{3} \mathrm{H}_{6}$ and $\mathrm{H}_{2} \mathrm{O}$ molecules. In this new adduct, net APT localized charges on lithium and oxygen are 0.768 and -0.657 , respectively, and -0.177 on the $\mathrm{C}_{\text {terminal }}$, while those on $\mathrm{C}_{\text {central }}$ and the methyl group carbon are very small. A detailed analysis of the valence molecular orbitals does not show significant contributions from the alkali atomic orbitals, reflecting the essentially non-covalent interaction between participants. The M3 structure makes easy to interpret the endoergic processes leading either to the final products (1) or (2) by means of the dissociation of the $\mathrm{Li}-\mathrm{O}$ coordination interaction in the former case or, alternatively, of the $\mathrm{Li}-\mathrm{C}_{3} \mathrm{H}_{6}$ one in the latter.

\section{DISCUSSION}

\section{A. Lithium ion-induced dehydration and dehydrohalogenation processes}

For both dehydration and dehydrohalogenation processes, the M1 adduct structure can be considered as the equilibrium geometry of the collision complex (formed in the bimolecular process) that can be stabilized by infrared emission along their flying time (estimated in the $10^{-4} \mathrm{~s}$ range under experimental conditions) from the reaction zone to the ion detector, assuming their internal energy transfer to be fast enough (currently in the $10^{-13} \mathrm{~s}$ range). However, signals measured at the corresponding $\mathrm{m} / \mathrm{z}$ ratios include not only those structures 
near M1 that can be associated with stabilized intermediates but also any structure of the collision complex adopted along the reaction pathway but not yet rearranged into final reaction products (1) or (2). These considerations could explain, at least at a qualitative level, the difficulties found in fitting the corresponding excitation function to analytically simple models currently working satisfactorily in most simple reactions. ${ }^{27}$ As noticed in Section II, it was not possible to measure the excitation function for $\left[\mathrm{Li}-i-\mathrm{C}_{3} \mathrm{H}_{7} \mathrm{OH}\right]^{+}$, even though it is more stable than $\left[\mathrm{Li}-i-\mathrm{C}_{3} \mathrm{H}_{7} \mathrm{Br}\right]^{+}$. A possible interpretation could be found in terms of the much higher reactivity of $\left[\mathrm{Li}-i-\mathrm{C}_{3} \mathrm{H}_{7} \mathrm{OH}\right]^{+}$as a reaction intermediate even at low energies near the threshold (see Fig. 5) when compared with that of $\left[\mathrm{Li}-i-\mathrm{C}_{3} \mathrm{H}_{7} \mathrm{Br}\right]^{+}$as can be appreciated from Figures 1(b) and 2(b).

Inspection of the potential energy profiles along the reaction evolution given in Figures 2 and 5 (see also Tables III and IV) shows that both collision systems present a relatively deep potential energy well in the reactants' side of their PES of the full system. As commented in Secs. III B and IV B, the formation of adducts with the M1 structure can be interpreted as mainly due to long range ion-molecule interactions. This follows from the analysis of the quantum chemistry valence molecular orbitals in which the contribution of the lithium atomic orbitals can be completely neglected, pointing to an essentially non-covalent interaction between both adduct partners (similar results were also found for other alkali ion-molecule systems ${ }^{10-12}$ ). Taking into account that both $i-\mathrm{C}_{3} \mathrm{H}_{7} \mathrm{Br}$ and $i-\mathrm{C}_{3} \mathrm{H}_{7} \mathrm{OH}$ are both polar and polarizable, the former containing a highly polarizable, big-sized bromine atom and the latter the polar $\mathrm{OH}$ group, an important electrostatic ion-molecule interaction can be expected in both cases. In the first approach and in terms of simple, non-covalent model approximations, the interaction potential energy $V(r)$ at a fixed distance $r$ between the lithium ion and the center of the charge distribution of those molecules can be described mainly as a sum of the long-range ion-dipole (i-d) and ion-induced dipole (i-id) interactions involving the corresponding molecular polarizabilities $(\alpha)$ and dipole moment $(\mu) .{ }^{47,48}$ In such a model, $V(r)$ would be given by the well-known $-\alpha q^{2} / 2 r^{4}$ $-\mu q \cos \gamma / r^{2}$ equation where $q$ is the charge of the ion and $\gamma$ the angle between $r$ and $\mu$ vectors ${ }^{40}$ which describe $\mathrm{i}-\mathrm{d}$ and $\mathrm{i}$-id interactions, respectively. In this approach and using for $V(r)$ the M1 potential energy well depth calculated at the $a b$ initio level for both M1 structures, the associated distances $r$ were found to be about $3.1 \AA$ and $2.6 \AA$, respectively. These results agree well with the distances $(2.9 \AA$ and $2.5 \AA$ ) estimated from quantum chemistry structure calculations. Even though, as it is well known, a purely electrostatic ion-molecule interaction cannot fully describe adduct structures calculated at the quantum chemistry level, these estimated distances provide a first approach to a qualitative understanding of the adducts' formation, in which the positive lithium center is coordinated with the side of the molecule containing bromine or oxygen atoms, the M1 atomic centers having the highest negative density of charge, as shown by the quantum structure calculations.

Although the experimental excitation function for $\left[\mathrm{Li}-i-\mathrm{C}_{3} \mathrm{H}_{7} \mathrm{Br}\right]^{+}$adduct formation given in Fig. 1(a) shows the shape expected for barrierless ion-molecule chemical reactions, which is currently interpreted in terms of simple ion-molecule capture models (such as the LGS one, where the molecular polarizability controls the reactivity of the system), it proved unfeasible in the present case to fit satisfactorily the measured cross sections as a simple function on $\mathrm{E}^{-1 / 2}$. More elaborated yet still simple models, taking into account the combined ion-induced dipole and ion-permanent dipole models (such as the so-called locked dipole, frozen dipole, or the average dipole orientation ones, ${ }^{49}$ which include several fitting parameters and combine energy dependences on $\mathrm{E}$ and $\mathrm{E}^{-1 / 2}$ ) while being also able to qualitatively describe the cross section energy dependences, did not fit adequately the experimental results.

Assuming that the reactive collisions evolve adiabatically on the ground singlet PES along the reaction pathways shown in Figures 2 and 5 (see also Tables I and III), the exothermic character of the reaction (1) in both systems is evident, while (2) is slightly endothermic for $\mathrm{Li}^{+}+i-\mathrm{C}_{3} \mathrm{H}_{7} \mathrm{Br}$ and exothermic for $\mathrm{Li}^{+}+i-\mathrm{C}_{3} \mathrm{H}_{7} \mathrm{OH}$. Accordingly, for the former system, which has no energy barrier over reactants, the excitation function for reaction (1) does not show an energy threshold (Fig. 1(b)), while for the endothermic reaction (2) an experimental energy threshold (around $0.1 \mathrm{eV}$ ) is found in a good agreement with the calculated reaction heat $(0.09 \mathrm{eV})$, its measured cross sections being smaller than those for reaction (1). For the $\mathrm{Li}^{+}+i-\mathrm{C}_{3} \mathrm{H}_{7} \mathrm{OH}$ system, while both reactions (1) and (2) are exothermic, the potential energy barrier associated with TS1 (see Figure 5), lying at $0.279 \mathrm{eV}$ over reactants, leads to finding a threshold energy for both channels. As can be seen in Figure 4(a), the excitation function for reaction (1) seems to show a maximum in the $0.20-0.30 \mathrm{eV}$ energy range, quite like the height of the ZPE potential energy barrier. Even though a similar behavior is to be expected for reaction (2), the measured excitation function did not permit even a rough estimation of the threshold energy, due perhaps to a sum of the effects of a very high reactivity near the nominal energy threshold and of the experimental collision energy spread. From the measured reaction cross section values, it can be inferred that both $\mathrm{Li}^{+}+i-\mathrm{C}_{3} \mathrm{H}_{7} \mathrm{Br}$ and $\mathrm{Li}^{+}+i-\mathrm{C}_{3} \mathrm{H}_{7} \mathrm{OH}$ systems show a high reactivity in the range of collision energies studied particularly for the latter system at low energies. Assuming a thermal Maxwell-Boltzmann distribution both for the molecules' internal rotational and vibrational states and for the collision energies and taking into account that measured reaction cross sections include all state-to-state cross sections, the thermal rate constants $k(T)$ can be calculated ${ }^{40}$ at $303 \mathrm{~K}$ (the temperature of the target molecule inside the reaction chamber) from the excitation functions. Calculated rate constants for reactions (1) and (2) in $\mathrm{Li}^{+}+i-\mathrm{C}_{3} \mathrm{H}_{7} \mathrm{Br}$ collisions are around $4.6 \times 10^{-11} \mathrm{~cm}^{3} \mathrm{~s}^{-1} \mathrm{molec}^{-1}$ and $5.7 \times 10^{-14} \mathrm{~cm}^{3}$ $\mathrm{s}^{-1}$ molec $^{-1}$, respectively, while those in the $\mathrm{Li}^{+}+i-\mathrm{C}_{3} \mathrm{H}_{7} \mathrm{OH}$ system are $1.6 \times 10^{-10} \mathrm{~cm}^{3} \mathrm{~s}^{-1}$ molec $^{-1}$ and $1.4 \times 10^{-9} \mathrm{~cm}^{3} \mathrm{~s}^{-1}$ molec $^{-1}$, respectively. The former reaction was not considered by Allison and Ridge ${ }^{15}$ while for the latter, although explicitly included in their work, they did not observe reactivity. Present estimated rate constant values in the $\mathrm{Li}^{+}+i-\mathrm{C}_{3} \mathrm{H}_{7} \mathrm{Br}$ system are clearly under the estimated range $\left(2-10 \times 10^{-10} \mathrm{~cm}^{3} \mathrm{~s}^{-1}\right.$ molec $^{-1}$ ) for reactive systems reported in Ref. 15, while in the $\mathrm{Li}^{+}+i-\mathrm{C}_{3} \mathrm{H}_{7} \mathrm{OH}$ one, estimated present values being just in 
the limit of those reported in that reference, and this could help to explain its failure to assign reactivity to $\mathrm{Li}^{+}+i-\mathrm{C}_{3} \mathrm{H}_{7} \mathrm{OH}$ collisions.

About the decompositions (3) in Figures 2 and 5, it can be appreciated that both reactions are endothermic, the energy threshold being estimated from the calculated $\Delta_{\mathrm{r}} H^{\mathrm{o}}$ value, and evolve on the same PES on which reactions (2) and (3) take place. Experimental excitation functions (Figures 1(c) and 4(b)) show the expected energy dependence for endothermic reactions. Experimental energy thresholds can be estimated at around $0.50 \mathrm{eV}$ for $\mathrm{Li}^{+}+i-\mathrm{C}_{3} \mathrm{H}_{7} \mathrm{Br}$ and $1.50 \mathrm{eV}$ for $\mathrm{Li}^{+}+i-\mathrm{C}_{3} \mathrm{H}_{7} \mathrm{OH}$, while calculated values are $0.689 \mathrm{eV}$ and $1.892 \mathrm{eV}$, respectively. Taking into account experimental uncertainties on both the cross section and on the collision energies, calculated and estimated energy thresholds for reactions (3) agree well enough in both reactive systems. In the post-threshold energy region, excitation functions for both reactions (3) display a maximum and then smoothly decrease at higher collision energies. At low energies, cross section values for reactions (3) are smaller than those for reactions (1) and (2) in both reactive systems. Furthermore, reaction (3) reaches its maximum in the energy range where reactions (1) and (2) are clearly diminished. In Figures 1(c) and 4(b) it can also be seen that, at energies around the reaction (3) maxima, the function for $\mathrm{C}_{2} \mathrm{H}_{3}{ }^{+}$formation via reaction (4) starts to grow up, showing similar energy dependences for both collision systems. As commented in the corresponding experimental section, reaction (4) can take place only when the total energy content of the parent $\mathrm{C}_{3} \mathrm{H}_{7}{ }^{+}$is high enough to allow its dissociation as a unimolecular reaction, thus showing the corresponding energy threshold. It is important to remark that reaction (4) takes place on a PES different from that on which reactions (1)-(3) evolve adiabatically since reaction (4) are secondary reactive processes occurring when the total energy of the parent molecule is high enough to allow the atomic rearrangement and the carbon-carbon bond cleavage involved in the reaction. ${ }^{24}$ Despite the experimental uncertainties, threshold energies from Figures 1(c) and 4(b) can be estimated as being roughly about $3.0 \mathrm{eV}$ for both $\mathrm{Li}^{+}+i-\mathrm{C}_{3} \mathrm{H}_{7} \mathrm{Br}$ and $\mathrm{Li}^{+}$ $+i-\mathrm{C}_{3} \mathrm{H}_{7} \mathrm{OH}$, as can be expected since they are really the same chemical reaction in both cases. This value is in good-enough agreement with one $(2.83 \mathrm{eV})$ calculated previously by some of the authors. ${ }^{24}$ At a qualitative level, the fall in the $\mathrm{C}_{3} \mathrm{H}_{7}{ }^{+}$excitation function can be attributed at least partially to the aperture of channel (4) and also to the decrease in $\mathrm{C}_{3} \mathrm{H}_{7}+$ production when collision energies increases, as is usual in reactions with an energy barrier. As to its shape, the excitation function for $\mathrm{C}_{2} \mathrm{H}_{3}{ }^{+}$is similar to that for its $\mathrm{C}_{3} \mathrm{H}_{7}{ }^{+}$parent.

\section{B. A brief survey on similarities and differences on alkali ions induced elimination reactions on collisions with $i-\mathrm{C}_{3} \mathrm{H}_{7} \mathrm{Br}$ and $i-\mathrm{C}_{3} \mathrm{H}_{7} \mathrm{OH}$ gas phase molecules}

When comparing $\mathrm{Li}^{+}, \mathrm{Na}^{+}$, or $\mathrm{K}^{+}$induced dehydrohalogenation reactions of the $i-\mathrm{C}_{3} \mathrm{H}_{7} \mathrm{Br}$ with those corresponding dehydration reactions of the $i-\mathrm{C}_{3} \mathrm{H}_{7} \mathrm{OH}$ (with all reactants in their electronic ground singlet state), we found a set of similarities among them, not the lesser of them being that they all lead to products formed in channels (1) and (2), but there are also significant differences in reactivity which deserve further consideration.

Considering $\mathrm{Li}^{+}+i-\mathrm{C}_{3} \mathrm{H}_{7} \mathrm{Br}$, it can be seen from $a b$ initio calculations given in Figure 2 that the potential energy profile along the reaction pathway shows reaction (1) to be slightly exothermic while reaction (2) is slightly endothermic and that the reaction evolves from reactants to products without any potential energy barrier higher than the asymptotic energies of reactants or products. In the case of $\mathrm{Na}^{+}+i-\mathrm{C}_{3} \mathrm{H}_{7} \mathrm{Br}$, reactions (1) and (2) are both endothermic, and the reaction pathway shows a small transition state potential energy barrier over reactants ${ }^{50}$ but slightly below the asymptotic energies of both reaction products. However, in the case of $\mathrm{K}^{+}+i-\mathrm{C}_{3} \mathrm{H}_{7} \mathrm{Br}$, both reactions (1) and (2) are also endothermic ${ }^{22}$ but there is a high transition potential energy barrier over the asymptotic energy of both reaction products. Taking into account the ab initio information on the adiabatic PESs of all three systems, their reactivity can be mainly correlated with the height of the transition state potential energy barrier between reactants and products. In fact, the barrierless $\mathrm{Li}^{+}+i-\mathrm{C}_{3} \mathrm{H}_{7} \mathrm{Br}$ system (only reaction (2) is slightly endothermic) shows the highest reactivity. The behavior of the $\mathrm{Na}^{+}+i-\mathrm{C}_{3} \mathrm{H}_{7} \mathrm{Br}$ system is quite similar to the lithium one. The reactivity in both channels was also enough to allow an estimation of the corresponding rate constants $\left(5.1 \times 10^{-13} \mathrm{~cm}^{3} \mathrm{~s}^{-1}\right.$ molec $^{-1}$ for reaction (1) and $2.6 \times 10^{-13} \mathrm{~cm}^{3} \mathrm{~s}^{-1} \mathrm{molec}^{-1}$ for (2), as given in Ref. 50) although the reactivity of the $\mathrm{Na}^{+}+i-\mathrm{C}_{3} \mathrm{H}_{7} \mathrm{Br}$ system is two orders of magnitude lower than the $\mathrm{Li}^{+}+i-\mathrm{C}_{3} \mathrm{H}_{7} \mathrm{Br}$ one. As to $\mathrm{K}^{+}+i-\mathrm{C}_{3} \mathrm{H}_{7} \mathrm{Br}$, quantum chemistry calculations ${ }^{22}$ show that both reactions (1) and (2) are much more endothermic that in the case of $\mathrm{Na}^{+}$but now the PES profile along the reaction pathway has a potential energy barrier much higher than the reaction endothermicity, and it proved impossible to measure the reactive excitation function for reaction (1) while for (2) a very low value $\left(5 \times 10^{-27} \mathrm{~cm}^{3} \mathrm{~s}^{-1} \mathrm{molec}^{-1}\right)^{22}$ was found.

Another typical feature common to all three $\mathrm{M}^{+}+$ $i-\mathrm{C}_{3} \mathrm{H}_{7} \mathrm{Br}$ (with $\mathrm{M}=\mathrm{Li}, \mathrm{Na}, \mathrm{K}$ ) systems is the presence of a relatively deep potential energy well (before the transition potential energy barrier just mentioned), located at the entrance of the reaction path valley and whose depth diminishes going from $\mathrm{Li}^{+}$to $\mathrm{K}^{+}$. This structure can be seen as being the ion-molecule adducts resulting mainly from the ionmolecule interaction of non-covalent character that also plays the role of intermediates associated with the collision complex. Excitation functions have been experimentally measured for all three systems. This collision complex leads to the final reaction products by a translation to vibration energy transfer $(T \rightarrow V)$ process where non-adiabatic couplings between vibrational modes get the necessary energy to those vibration modes more involved in the rearrangement finally leading to elimination reactions (1) or (2).

Moving to the case of $\mathrm{M}^{+}+i-\mathrm{C}_{3} \mathrm{H}_{7} \mathrm{OH}$ (with $\mathrm{M}=\mathrm{Li}$, $\mathrm{Na}, \mathrm{K}$ ) collisions, the evolution of their potential energy profiles along the reaction pathway shows a similar pattern to those found in the case of the $i-\mathrm{C}_{3} \mathrm{H}_{7} \mathrm{Br}$. Thus, they have in common a transition state potential energy barrier (at the exit of the ion-molecule potential energy well) that for all three systems is higher than the corresponding asymptotic energies 
of reactions (1) and (2), this energy difference increasing on going from lithium to potassium.

As in the case of isopropyl bromide, for $\mathrm{Li}^{+}+i-\mathrm{C}_{3} \mathrm{H}_{7} \mathrm{OH}$ both reactions (1) and (2) have been observed and their rate constants estimated, the most exothermic reaction (2) being faster according to a statistical interpretation of the reactions rates. ${ }^{40}$ Moreover, this system is the most reactive one among those involving the isopropyl alcohol. This also is in agreement with the lower potential energy barrier calculated for the different alkali-ion alcohol systems. In $\mathrm{Na}^{+}+i$ $\mathrm{C}_{3} \mathrm{H}_{7} \mathrm{OH}$, the exothermic character of reactions (1) and (2) is smaller than in the case of the lithium ion, with the latter being faster at some $9.6 \times 10^{-9} \mathrm{~cm}^{3} \mathrm{~s}^{-1} \mathrm{molec}^{-1}$, while is proved impossible to measure the excitation function for the more endothermic reaction (1) experimentally. ${ }^{50}$ For this system the transition state potential energy barrier increases. For $\mathrm{K}^{+}+i-\mathrm{C}_{3} \mathrm{H}_{7} \mathrm{OH}$, reaction (1) is endothermic, while (2) is exothermic but the transition state potential energy barrier is so much higher than the asymptotic one of both reactions that it was not possible to measure their excitation functions. ${ }^{22}$

As in the case of reactions with isopropyl bromide, the presence of the potential energy well (mainly due to ionmolecule interactions which stabilize the collision complex) allows measuring the adduct excitation functions in reactions with $\mathrm{Na}^{+}$and $\mathrm{K}^{+}$but not $\mathrm{Li}^{+}$. This is probably a consequence of the high reactivity of the $\left[\mathrm{Li}-i-\mathrm{C}_{3} \mathrm{H}_{7} \mathrm{OH}\right]^{+}$since, while being the most stable structure of the three adducts, it needs to overcome the lowest potential energy barrier in order to arrive at products (1) and (2). This would mean that the transient species' lifetime will be so reduced that, although detected experimentally, it proved unfeasible to measure the corresponding excitation function.

About decomposition reactions (3) resulting from a heterolytic cleavage of the essentially covalent bond $\mathrm{C}_{\text {central }}-\mathrm{X}$ (with $\mathrm{X}=\mathrm{Br}, \mathrm{OH}$ ) and producing $\mathrm{C}_{3} \mathrm{H}_{7}{ }^{+}$, the corresponding excitation functions could be measured for all collision systems. For $\mathrm{M}^{+}+i-\mathrm{C}_{3} \mathrm{H}_{7} \mathrm{Br}$, the reaction endothermicity increases from lithium to potassium ions, being reaction cross sections for $\mathrm{Li}^{+}$and $\mathrm{Na}^{+}$in the range of a few $\AA^{2}$ (although something larger in the case of $\left.\mathrm{Na}^{+}\right)^{50}$ while those for $\mathrm{K}^{+}$are in the tenths $\AA^{2}$ range. ${ }^{22}$ For $\mathrm{M}^{+}+i-\mathrm{C}_{3} \mathrm{H}_{7} \mathrm{OH}$ a similar behavior is also found, showing large cross section values in collisions with $\mathrm{Li}^{+}$and $\mathrm{Na}^{+}$(in the high $10 \AA^{2}$ range for the former and of a few $10^{2} \AA^{2}$ range for the latter) while for $\mathrm{K}^{+}$, cross section values are in the $10^{-2} \AA^{2}$ range.

The strongly endothermic character of reaction (3) (as it was the case for (1) and (2)) requires a translational to vibrational energy transfer $(T \rightarrow V)$ in order to allow the ionmolecule adduct to decompose, and measured cross section values clearly indicate that $\mathrm{Li}^{+}$and $\mathrm{Na}^{+}$are rather more effective in promoting (3) than $\mathrm{K}^{+}$. A plausible and qualitative interpretation of this behavior could be the larger size of $\mathrm{K}^{+}$ compared to those $\mathrm{Na}^{+}$and $\mathrm{Li}^{+}$. This effect would also justify the later decomposition of $\mathrm{C}_{3} \mathrm{H}_{7}{ }^{+}$producing $\mathrm{C}_{2} \mathrm{H}_{3}{ }^{+}$by reaction (4), for which measured cross section values are similar to those measured for reaction (3) in the case of $\mathrm{Li}^{+}$, not important or practically negligible for $\mathrm{Na}^{+}$and not present in $\mathrm{K}^{+}$. This effect (which is entirely similar in the case of $i-\mathrm{C}_{3} \mathrm{H}_{7} \mathrm{Br}$ and $i-\mathrm{C}_{3} \mathrm{H}_{7} \mathrm{OH}$ molecules colliding with alkali ions) seems to correlate the larger reactivity and efficiency in promoting a $T \rightarrow V$ energy transfer by $\mathrm{Li}^{+}$with its smaller size but this assertion would require a theoretical dynamic study to confirm it.

\section{CONCLUSIONS}

Using the experimental RF-GIB technique, the gas-phase, $\mathrm{Li}^{+}$collision induced $i-\mathrm{C}_{3} \mathrm{H}_{7} \mathrm{Br}$ dehydrohalogenation and $i-\mathrm{C}_{3} \mathrm{H}_{7} \mathrm{OH}$ dehydration have been studied, being all reactants in their ground electronic state. A mass spectrometry analysis of their different ionic products proved the existence of several reaction channels, the corresponding excitation functions being measured for the first time in absolute units in the $0.10-10.00 \mathrm{eV}$ collision energy range. For both collision systems, $\mathrm{Li}^{+}$was able to attach itself to the $\mathrm{C}_{3} \mathrm{H}_{6}$ unsaturated hydrocarbon or to the eliminated $\mathrm{HBr}$ or $\mathrm{H}_{2} \mathrm{O}$ molecules. Moreover, in the case of the $i-\mathrm{C}_{3} \mathrm{H}_{7} \mathrm{Br}$ the formation of the stable $\left[\mathrm{Li}-i-\mathrm{C}_{3} \mathrm{H}_{7} \mathrm{Br}\right]^{+}$adduct was characterized and the corresponding excitation function measured while in the case of $i-\mathrm{C}_{3} \mathrm{H}_{7} \mathrm{OH}$ this was not possible because of the large measurement uncertainties. The high reactivity of the $\mathrm{Li}^{+}+i-\mathrm{C}_{3} \mathrm{H}_{7} \mathrm{OH}$ system, even at very low collision energies, could explain at least qualitatively the experimental incapability for measuring the excitation function of the corresponding adduct formation. Moreover, the products from adduct decomposition reactions (3) were characterized and their excitation functions measured, as well as those of the $\mathrm{C}_{3} \mathrm{H}_{7}{ }^{+}$unimolecular decomposition when total energy was enough to allow reaction (4) to take place. Experimental studies are accompanied by ab initio quantum chemistry calculations at the MP2 level, and these allowed the characterization of the different reaction channels as well as the stationary points explored by the system along the reaction path from reactants to products on the adiabatic singlet ground state PES. The evolution of the potential energy profile along the reaction path on the PES allows a qualitative interpretation of the cross section energy dependences for the different reaction channels. Experimentally estimated threshold energies are in agreement with those obtained in quantum chemistry calculations, confirming the important role played by the non-covalent interactions in the formation of the ionmolecule adducts and the evolution of the different reaction channels. A full comprehension of the different dynamical effects associated with reaction evolutions would require a theoretical dynamical calculation, but unfortunately the absence of analytical PESs for the systems studied here, and the prohibitive computer time requirement for a direct trajectory study of those reactions does not allow a full dynamics interpretation of the experimental studies.

\section{ACKNOWLEDGMENTS}

This work has been supported by the Spanish Ministerio de Economia y Competividad (MINECO Project Nos. CTQ2013-41307-P and CTQ2016-76423-P). Thanks are also due to the Generalitat de Catalunya-AGAUR (Project No. 2013 SGR 25) and to the Consorci de Serveis Universitaris de Catalunya (CSUC) and the Fundació Catalana per a la Recerca for allocating supercomputing time. 
${ }^{1}$ M. H. Rees, "Chemical ionic reactions in the thermosphere," in Physics and Chemistry of the Upper Atmosphere (Cambridge University Press, Cambridge, UK, 1989), pp. 278-281.

${ }^{2}$ J. De Andrés, J. M. Lucas, M. Albertí, J. M. Bofill, and A. Aguilar, Chem. Phys. 462, 104 (2015).

${ }^{3}$ W. Klemperer and V. Vaida, Proc. Natl. Acad. Sci. U. S. A. 103, 10584 (2006).

${ }^{4}$ P. Bryans, W. Mitthumsiri, D. W. Savin, N. R. Badnell, T. W. Gorczyca, and J. M. Laming, Astrophys. J., Suppl. Ser. 167, 343 (2006).

${ }^{5}$ M. Labuda, Y. S. Tergiman, M. C. Bacchus-Montabonel, and J. E. Sienkiewicz, Int. J. Mol. Sci. 4, 265 (2004).

${ }^{6}$ M. Sabidó, J. de Andrés, J. Sogas, J. M. Lucas, M. Alberti, J. M. Bofill, and A. Aguilar, J. Chem. Phys. 121, 5284 (2004).

${ }^{7}$ M. M. Kish and C. Wesdemiotis, J. Phys. Chem. B 108(9), 3086 (2004).

${ }^{8}$ D. Kim, S. Hu, P. Tarakeshwar, and K. S. Kim, J. Phys. Chem. A 107(8), 1228 (2003).

${ }^{9}$ T. B. McMahon and G. Ohanessian, Chem. Eur. J. 6, 2931-294 (2000).

${ }^{10}$ M. Sabidó, J. M. Lucas, J. de Andrés, J. Sogas, M. Albertí, A. Aguilar, D. Bassi, D. Ascenzi, P. Franceschi, P. Tosi, and F. Pirani, Chem. Phys. Lett. 442, 28 (2007).

${ }^{11}$ J. M. Lucas, J. de Andrés, E. LoÌ'pez, M. Albertí, J. M. Bofill, D. Bassi, D. Ascenzi, P. Tosi, and A. Aguilar, J. Phys. Chem. A 113, 14766 (2009).

${ }^{12}$ E. López, J. M. Lucas, J. de Andrés, M. Albertí, J. M. Bofill, D. Bassi, and A. Aguilar, Phys. Chem. Chem. Phys. 13, 15977 (2011).

${ }^{13}$ R. D. Wieting, R. H. Staley, and J. L. Beauchamp, J. Am. Chem. Soc. 97, 924 (1975).

${ }^{14}$ J. Allison and D. P. Ridge, J. Am. Chem. Soc. 98, 7445 (1976).

${ }^{15}$ J. Allison and D. P. Ridge, J. Am. Chem. Soc. 101, 4998 (1979).

${ }^{16}$ W. R. Creasy and J. M. Farrar, J. Chem. Phys. 87, 5280 (1987).

${ }^{17}$ W. R. Creasy and J. M. Farrar, J. Phys. Chem. 89, 3952 (1985).

${ }^{18}$ J. M. Lucas, J. de Andrés, J. Sogas, M. Albertí, J. M. Bofill, D. Bassi, D. Ascenzi, P. Tosi, and A. Aguilar, J. Chem. Phys. 131, 024306 (2009).

${ }^{19}$ J. M. Lucas, J. de Andrés, M. Albertí, J. M. Bofill, D. Bassi, and A. Aguilar, Phys. Chem. Chem. Phys. 12, 13646 (2010).

${ }^{20}$ J. Aguilar, J. M. Lucas, J. de Andrés, M. Albertí, D. Bassi, and A. Aguilar, Phys. Chem. Chem. Phys. 13, 18581 (2011).

${ }^{21}$ J. Aguilar, J. M. Lucas, J. de Andrés, M. Albertí, D. Bassi, and A. Aguilar, J. Chem. Phys. 138, 184310 (2013).

${ }^{22}$ E. López, J. M. Lucas, J. de Andrés, M. Albertí, J. M. Bofill, D. Bassi, and A. Aguilar, J. Chem. Phys. 141, 164310 (2014).

${ }^{23}$ H. Koizumi and P. B. Armentrout, J. Chem. Phys. 119, 12819 (2003).

${ }^{24}$ J. M. Lucas, J. de Andrés, M. Albertí, J. M. Bofill, and A. Aguilar-Navarro, Int. J. Quantum Chem. 111, 493 (2011).
${ }^{25}$ J. H. Batey and J. M. Tedder, J. Chem. Soc., Perkin Trans. 2, 1263 (1983).

${ }^{26} \mathrm{~J}$. Aguilar, "Estudi experimental i teòric de la dinàmica de les reaccions ió-molècula," Ph.D. thesis, University of Barcelona, 2014.

${ }^{27}$ K. M. Ervin and P. B. Armentrout, J. Chem. Phys. 83, 166 (1985).

${ }^{28}$ P. J. Chantry, J. Chem. Phys. 55, 2746 (1971).

${ }^{29}$ C. Lifshitz, R. L. C. Wu, T. O. Tiernan, and D. T. Terwilliger, J. Chem. Phys. 68, 247 (1978).

${ }^{30}$ C. G. Schlier, Chem. Phys. 126, 73 (1988).

${ }^{31}$ C. Møller and M. S. Plesset, Phys. Rev. 46(7), 618 (1934).

${ }^{32}$ C. M. Aikens, S. P. Webb, R. L. Bell, G. D. Fletcher, M. W. Schmidt, and M. S. Gordon, Theor. Chem. Acc. 110, 233 (2003).

${ }^{33}$ M. J. Frisch, G. W. Trucks, H. B. Schlegel, et al., Gaussian 03, Revision E.01, Gaussian, Inc., Wallingford CT, 2004.

${ }^{34}$ M. Head-Gordon, J. A. Pople, and M. J. Frisch, Chem. Phys. Lett. 153, 503 (1988).

${ }^{35}$ M. J. Frisch, M. Head-Gordon, and J. A. Pople, Chem. Phys. Lett. 166, 275 (1990).

${ }^{36}$ C. Estarellas, X. Lucas, A. Frontera, D. Quiñonero, and P. M. Deyà, Chem. Phys. Lett. 489, 254 (2010).

${ }^{37}$ K. Fukui, J. Phys. Chem. 74, 4161 (1970).

${ }^{38}$ M. S. Gordon and M. W. Schmidt, in Theory and Applications of Computational Chemistry:The First Forty Years, edited by C. E. Dykstra, G. Frenking, K. S. Kim and G. E. Scuseria (Elsevier, 2005), p. 1167.

${ }^{39}$ C. Gonzalez and H. B. Schlegel, J. Chem. Phys. 90, 2154 (1989).

${ }^{40}$ R. D. Levine, Molecular Reaction Dynamics (Cambridge University Press, 2005), pp. 42, 92, 249, 252.

${ }^{41}$ J. de Andrés, J. M. Lucas, M. Albertí, J. M. Bofill, A. Belyaev, and A. Aguilar, J. Chem. Phys. 137, 154202 (2012).

${ }^{42}$ R. G. Parr and W. Yang, Density-Functional Theory of Atoms and Molecules (Oxford University Press, 1989), Vol. 16.

${ }^{43}$ P. Hohenberg and W. Kohn, Phys. Rev. 136, B864 (1964).

${ }^{44}$ J. P. Stephens, F. J. Devlin, C. F. Chabalowsky, and M. J. Frisch, J. Phys. Chem. 98, 11623 (1994).

${ }^{45}$ P. J. Stephens, K. J. Jalkanen, and R. W. Kawiecki, J. Am. Chem. Soc. 112, 6518 (1990).

${ }^{46}$ M. M. C. Ferreira, J. Mol. Struct. 294, 75 (1993).

${ }^{47}$ CRC Handbook of Chemistry and Physics, 77th ed., edited by R. D. Lide (CRC, Boca Raton, FL, 1996).

${ }^{48}$ CRC Handbook of Chemistry and Physics, 84th ed., edited by R. D. Lide (CRC, Boca Raton, FL, 2003-2004).

${ }^{49}$ Gas Phase Ion Chemistry, edited by M. T. Bowers (Academic Press, New York, San Francisco, London, 1979), Vol. 1, Chap. 3, pp. 84-117.

${ }^{50}$ E. López, J. M. Lucas, J. de Andrés, M. Albertí, J. M. Bofill, and A. Aguilar, J. Phys. Chem. A 120, 4758 (2016). 